\title{
Activation of Akt by the Mammalian Target of Rapamycin Complex 2 Renders Colon Cancer Cells Sensitive to Apoptosis Induced by Nitric Oxide and Akt Inhibitor
}

Rahamata Ali-Boina ${ }^{1-3}$, Marion Cortier ${ }^{1-3}$, Nathalie Decologne ${ }^{1-3}$, Cindy Racoeur-Godard ${ }^{1-3}$, Cédric Seignez ${ }^{1-3}$, Myriam Lamrani ${ }^{1-3}$, Jean $^{-}$

François Jeannin ${ }^{1-3}$, Catherine Paul ${ }^{1-3}$ and Ali Bettaieb ${ }^{1-3 *}$

${ }^{1}$ EPHE, Tumor Immunology and Immunotherapy Laboratory, Dijon, F-21000, France

'Inserm U866, Dijon, F-21000, France

${ }^{3}$ University of Burgundy, Dijon, F-21000, France

\begin{abstract}
Clinical and preclinical studies have shown that inhibition of Akt or mammalian target of rapamycin (mTOR) signaling alone is not sufficient to treat colorectal carcinoma. Recently, the nitric oxide (NO) donor glyceryl trinitrate (GTN) was reported to revert the resistance to anticancer agents. In search of combination therapies, we show here that concomitant treatment with GTN, an Akt inhibitor, triciribine and a non-specific protein kinase A inhibitor, H89 synergistically induced apoptosis of rapamycin-resistant colon cancer cells as evaluated by Hoechst staining. Biochemical analyses as western blotting indicated that treatment of cells with $\mathrm{H} 89$ induced activation of Akt and p70S6K1 as attested by their phosphorylation. This effect did not blockade GTN/H89-inducing apoptosis but restrained it since addition of triciribine dramatically enhanced apoptosis. This phenomenal synergistic effect was correlated to a breaking-down of the expression of phosphorylated Akt and p70S6K1. Finally, transient siRNAmediated knockdown of the mTORC2 protein, rictor, significantly increased apoptosis induced by GTN/H89. In contrast, pharmacologically inhibition of mTORC1 and siRNA-mediated knockdown of the p70S6K1 did not modified GTN/H89 priming of apoptosis. These findings provide a preclinical proof of concept-for-combination therapy to enhance therapeutic efficacy in rapamycin-resistant colorectal carcinoma.
\end{abstract}

Keywords: Glyceryl trinitrate; H89; Triciribine; mTORC2; Colon cancer

\section{Introduction}

Colorectal cancer (CRC) is a major health issue. It is one of the major causes of cancer mortality worldwide and continues to be the third most common cause of cancer-related deaths in the U.S [1]. Despite the new anticancer drugs such as irinotecan and oxaliplatin, the median survival for patients with metastatic CRC is still less than 20 months, which underscores the urgent need for the development of more efficient novel therapeutic approaches [2]. Novel compounds have been developed with the aim of targeting specific tumor promoting signaling pathways in order to induce tumor regression [3].

Akt, a serine/threonine protein kinase, coordinates a variety of intracellular signals involved in cell cycle progression, apoptosis, and cell metabolism, as (i) the increase in the levels of cyclin D1 and a reduction of the cyclin-dependent kinase (Cdk) inhibitors $\mathrm{p} 21^{\mathrm{cip} 1}$ and p2 $7^{\mathrm{kip} 1}[4,5]$, (ii) the inhibition of two pro-apoptotic proteins, caspase 9 and Bad [6,7], (iii) the activation of mTOR [8,9]. Consequently, its constitutive activation contributes to aberrant cell cycle regulation, a hallmark of many cancers [10]. The phosphorylation of Akt is necessary to mediate the phosphatidylinositol 3-kinase (PI3K) signaling, specially on its Threonine 308 which is required in the activation loop by the phosphoinositide-dependent kinase 1 (PDK1). Another important kinase that is activated downstream of AKT is mTOR, a serine/ threonine kinase, that regulates two distinct cellular complexes: mTOR complex 1 (mTORC1) and mTOR complex 2 (mTORC2). mTORC1 includes mTOR, mTOR regulatory-associated protein of mTOR (Raptor), mLST8, and prolin-rich Akt substrate 40 (PRAS40), whereas mTORC2 consists of mTOR, mLST8, rapamycin-insensitive companion of mTOR (Rictor), stress-activated MAPK-interacting protein 1 (Sin1), and PROTOR [9].
Although Akt phosphorylates and then activates components of mTORC1, it is directly phosphorylated on serine 473 and activated by mTORC2 [8]. Thus, Akt and mTOR pathways act together to promote cell growth, division and survival.

Amplification and overexpression of Akt and activation of mTOR pathways are frequently detected in a number of human tumors including colon [11]. For these reasons, these kinases represent a highly attractive target for novel cancer therapies [12]. It has been reported that inhibition of Akt phosphorylation by PI3K/Akt inhibitor enhances apoptosis induced by chemotherapy agents and radiation. This occurs only in cells with high Akt/PKB activity [13]. Previous studies have also demonstrated that some chemotherapy or cytotoxic agents inactivate Akt, thus causing or enhancing apoptosis [14-16]. Recently, it has been shown that Akt phosphorylation at serine 473 predicts benefit from the sequential addition of paclitaxel to adjuvant doxorubicin plus cyclophosphamide chemotherapy in patients with node-positive breast cancer [17].

New treatment regimens are also introduced that maximize the

*Corresponding author: Ali Bettaieb, Laboratoire d'Immunologie et Immunothérapie des Cancers, EA 7269 de l'Université de Bourgogne-EPHE faculté de Médecine, 7 boulevard Jeanne d'Arc, 21079 Dijon, France, Tel: 00333 803934 51; Fax: 00333803934 34; E-mail: ali.bettaieb@u-bourgogne.fr

Received October 21, 2013; Accepted December 24, 2013; Published December 31,2013

Citation: Ali-Boina R, Cortier M, Decologne N, Racoeur-Godard C, Seignez C et al. (2013) Activation of Akt by the Mammalian Target of Rapamycin Complex 2 Renders Colon Cancer Cells Sensitive to Apoptosis Induced by Nitric Oxide and Akt Inhibitor. J Carcinog Mutagen S8: 004. doi:10.4172/2157-2518.S8-004

Copyright: (C) 2013 Ali-Boina R, et al. This is an open-access article distributed under the terms of the Creative Commons Attribution License, which permits unrestricted use, distribution, and reproduction in any medium, provided the original author and source are credited. 
Citation: Ali-Boina R, Cortier M, Decologne N, Racoeur-Godard C, Seignez C, et al. (2013) Activation of Akt by the Mammalian Target of Rapamycin Complex 2 Renders Colon Cancer Cells Sensitive to Apoptosis Induced by Nitric Oxide and Akt Inhibitor. J Carcinog Mutagen S8: 004. doi:10.4172/2157-2518.S8-004

therapeutic impact on cancer patients. Recently, Glyceryl Trinitrate (GTN), a member of the group of organic nitrate compounds [18] largely used in clinical medicine to treat angina pectoris via the release of nitric oxide (NO) or related species [19], has emerged as being beneficial in the treatment of patients suffering from cancer. A phase II trial [20] demonstrated an improvement in the overall response and time to progression in patients with inoperable non-small-cell lung cancer treated with GTN. Recently, another phase II trial [21] indicated that low doses of GTN could prevent prostate-specific antigen progression in men with recurrent cancer after primary treatment failure. We previously reported that, in vitro, high concentrations of GTN (in the micromolar range) induced caspase-mediated apoptosis and sensitized colon cancer cells to Fas/CD95 ligand-mediated cell death [22].

Here, we show that an unexpected activation of Akt by a protein kinase inhibitor renders human colon cancer cells sensitive to apoptosis induced by the combination of subtoxic concentrations of GTN and the Akt specific inhibitor triciribine.

\section{Materials and Methods}

\section{Reagents and antibodies}

GTN was purchased from Merck (Lyon, France), H89 [N-[2-(pBromocinnamylamino) ethyl]-5-isoquinolinesulfonamide.2HCl] from Interchim (Montluçon, France) and H7, H8, H9 were purchased from Enzo life sciences (Villeurbane, France). Triciribine was purchased from Calbiochem (Meudon, France) and the mTORC1 inhibitor, Rapamycin, from Santa Cruz (Santa Cruz Biotechnology, Santa Cruz, CA). Antibodies directed against Akt1, Akt2, rictor, and HSC70 were purchased from Santa Cruz Biotechnology (Santa Cruz, CA). Antibodies directed against Akt, phospho-Akt (S473), phospho-Akt (Thr308), p70S6K1, phospho-p70S6K1 were purchased from Cell signaling (Saint Quentin Yvelines, France).

\section{Cell culture and transfection experiments}

The SW480 and HCT8 human colorectal cancer cells were purchased from American Tissue Culture Collection (Manassas, VA). Each cell line was never continuously passed in culture for more than 3 months, and after that, a new vial of frozen cells was thawed. These cells were grown in 1:1 (vol/vol) DMEM: HAM-F10 (Biowhittaker, Fontenay-sous-Bois, France), supplemented with 5\% FCS (Gibco BRL, Eriny, France), and $2 \mathrm{mmol} / \mathrm{L} \mathrm{L}$-glutamine at $37^{\circ} \mathrm{C}$ in a dry atmosphere without supplementation with $5 \% \mathrm{CO}_{2}$ (the optimal conditions to induce apoptosis). Cells were routinely detached with $0.125 \%$ trypsin- $0.1 \%$ EDTA, and washed once in the culture medium before treatment. siRNAs (Santa Cruz Biotechnology, Santa Cruz, CA) were used to down-regulate p70S6K1 and rictor using the INTERFERin ${ }^{\mathrm{TM}}$ as outlined by the manufacturer (Polyplus transfection ${ }^{\mathrm{TM}}$ ).

\section{Patient samples}

Human tumor specimens were obtained from the Anticancer Centre Georges-François Leclerc (Dijon, France) under Institutional Review Board-approved studies. All patients provided written, informed consent

\section{Quantitation of apoptotic cells}

Cells $\left(3 \times 10^{5} / \mathrm{mL}\right)$ were treated with GTN $(10 \mu \mathrm{M})$ and/or H89 $(10$ $\mu \mathrm{M})$ with or without triciribine for 48 hours at $37^{\circ} \mathrm{C}$. After treatment, the whole population of cells including plastic-attached and floating cells was washed in cold phosphate buffer saline (PBS) and exposed for 15 minutes to $1 \mu \mathrm{g} / \mathrm{mL}$ Hoechst 33342 at $37^{\circ} \mathrm{C}$ before evaluating changes in cellular nuclear chromatin by fluorescence microscopy. The percentage of apoptotic cells (chromatin condensation and nuclear fragmentation) was determined by counting 300 cells in each sample.

\section{Phospho MAPK array}

A human phospho MAPK array kit (R\&D Systems) has been used for the parallel determination of the relative levels of phosphorylation of Mitogen-Activated Protein Kinases (MAPKs) and other serine/ threonine kinases, as outlined by the manufacturer. Briefly, cell lysate samples are diluted and mixed with a cocktail of biotinylated detection antibodies, and incubated overnight with the Proteome Profiler Human Phospho-MAPK Array. Streptavidin-HRP and chemiluminescence detection reagents are applied, and a signal is produced at each capture spot corresponding to the amount of phosphorylated protein bound.

\section{Immunoblot analysis}

Cells $\left(3 \times 10^{5} / \mathrm{mL}\right)$ were washed twice with cold PBS and whole-cell lysates were prepared in boiling buffer ( $1 \%$ sodium dodecyl sulphate (SDS), $1 \mathrm{mmol} / \mathrm{L}$ sodium-orthovanadate, $10 \mathrm{mmol} / \mathrm{L}$ Tris $\mathrm{pH} 7.4$ ). Lysates were harvested and protein concentration was measured by using a Bio-Rad DC protein assay kit. Fifty $\mu \mathrm{g}$ of proteins were incubated in loading buffer (125 mmol/L Tris-HCl, pH 6.8, 10\% ß-mercaptoethanol, $4.6 \%$ SDS, $20 \%$ glycerol and $0.003 \%$ bromophenol blue), separated by sodium dodecyl sulfate polyacrylamide gel electrophoresis (SDS-PAGE) and blotted onto PVDF membrane (BioRad). After blocking nonspecific binding sites for 2 hours with $8 \%$ non fat milk in TPBS (PBS 1X, Tween $200.1 \%$ ), the membrane was incubated overnight at $4^{\circ} \mathrm{C}$ with the primary Abs. After three washes in TPBS, the membrane was incubated with horseradish peroxidase-conjugated goat anti-mouse or anti-rabbit Abs for 45 minutes at room temperature, then washed three times in TPBS. Immunoblot was revealed using enhanced chemiluminescence detection kit (Luminol, Santa Cruz) and autoradiography.

\section{Immunohistochemical staining}

The expression level of phosphorylated Akt at serine 473 was performed on paraffin-embedded human colon tumours section on $5 \mu \mathrm{m}$ thick. Sections were deparaffined and antigen retrieval was performed before the inhibition of endogen peroxidase and the blocking of nonspecific sites with BSA and normal goat serum. Sections were incubated for $30 \mathrm{~min}$ with anti-phospho-Akt Ser473 monoclonal antibody (Cell Signaling) (1:100) at $4^{\circ} \mathrm{C}$ overnight followed by incubation with biotinylated link secondary antibody anti-rabbit for 45 min at room temperature. The slides were incubated with streptavidinlinked peroxidase for $30 \mathrm{~min}$ at room temperature. The slides were rinsed with $1 \mathrm{X}$ PBS-T three times for $5 \mathrm{~min}$ and the AEC solution (Vector laboratory) and were applied to cover specimen for $20 \mathrm{~min}$ at room temperature. The slides were rinsed with distilled water and counter stained with $10 \%$ haematoxylin. Finally, the slides were rinsed in a distilled water bath and mounted.

\section{Results}

\section{The protein kinase inhibitor $\mathrm{H89}$ increases sensitivity of colon cancer cells to GTN and Akt inhibitor}

Many colon cancer cells show resistance to Pi3K/Akt inhibitor treatment. Therefore, we were interested in determining which drugs are able to overcome resistance of colon cancer cells to Pi3K/Akt inhibitor. To address this, we first selected two human colon cancer cell lines SW 480 and HCT8 that have been found to be resistant to apoptosis induced by the specific Akt inhibitor triciribine (Figures 1A and B). The 
Citation: Ali-Boina R, Cortier M, Decologne N, Racoeur-Godard C, Seignez C, et al. (2013) Activation of Akt by the Mammalian Target of Rapamycin Complex 2 Renders Colon Cancer Cells Sensitive to Apoptosis Induced by Nitric Oxide and Akt Inhibitor. J Carcinog Mutagen S8: 004. doi:10.4172/2157-2518.S8-004

Page 3 of 9

two cell lines remained insensitive to triciribine even when exposed to high concentrations of the inhibitor (over than $30 \mu \mathrm{M}$ ) and exposed for up to $48 \mathrm{~h}$. It is worthy to note that the two cell lines expressed Aktl and Akt2 isoforms as assessed by western blotting (Figure 1C) but not the kinase phosphorylated forms occurring at serine 473 and threonine 308 (data not shown). The observation that nitric oxide (NO) can sensitize various cancer cells to apoptosis induced by cytotoxic agents [23] raises questions regarding whether NO might also be able to sensitize the two colon cancer cell lines to the Akt inhibitor. To test this hypothesis, cells were stimulated with a subtoxic concentration of the NO donor glyceryl trinitrate (GTN) and with increasing concentrations of triciribine for $24 \mathrm{~h}$ and $48 \mathrm{~h}$ time periods and apoptosis was assessed. As shown in Figures $1 \mathrm{~A}$ and $1 \mathrm{~B}$, GTN sensitized slightly but significantly cancer cells to triciribine-induced apoptosis. In search of effective combination therapies, we found that co-treatment of cells with the protein kinase inhibitor H89 and GTN and triciribine for $48 \mathrm{~h}$ dramatically induced apoptosis in the two cell lines (Figures 1A and 1B). We note that, longer incubation time and relative high concentrations of H89 sensitized
HCT8 cells to cell death induced by GTN and triciribine (Figure 1B). Interestingly, co-treatment with $\mathrm{H} 89$ and triciribine induced apoptosis in both cell lines but still much lower than their combination with GTN. These results indicated that the combination of a protein kinase inhibitor $\mathrm{H} 89$ with an Akt inhibitor and a NO donor synergistically and dramatically induced apoptosis of colon cancer cells.

\section{The protein kinase inhibitor $\mathrm{H89}$ activates the Akt/mTOR signaling pathway}

We were interested in determining how $\mathrm{H} 89$ could sensitize cells to apoptosis induced by GTN and triciribine. As H89 is a protein kinase inhibitor, we first examined whether its effect was due to its ability to inhibit protein kinases. Screening of SW480 cells for phosphorylation of 21 serine/threonine protein kinases using a phosphokinase array kit revealed that while $\mathrm{H} 89$ inhibited some target kinases such as JNK1, RSK1, and P38 $\gamma$, as expected (Table 1), it paradoxically induced phosphorylation of 2 isoforms of the protein kinase Akt, Akt1 and Akt2 (Table 1 and Figure 2A) without affecting the whole protein levels as
A

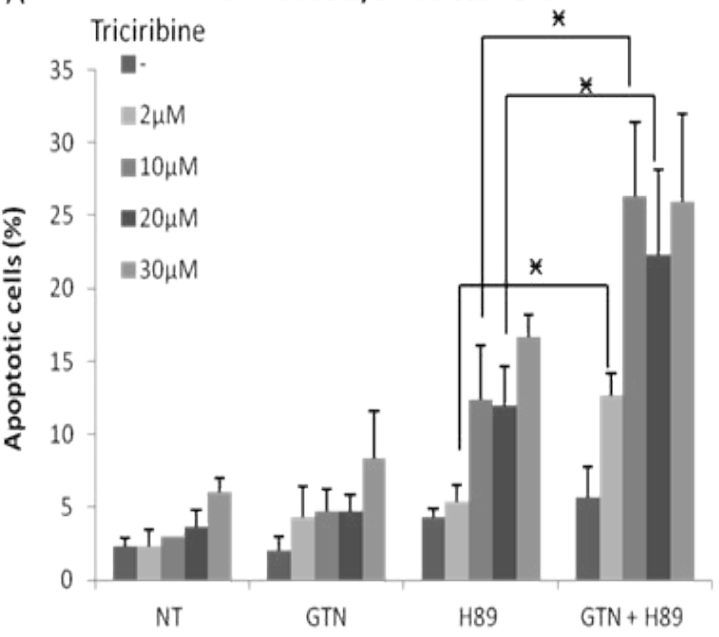

B

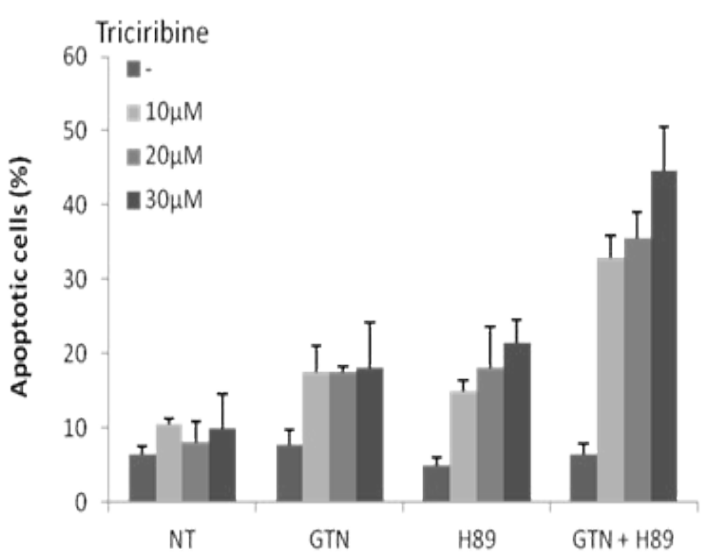

\section{SW480 cells/48 $\mathrm{h}$ treatment}

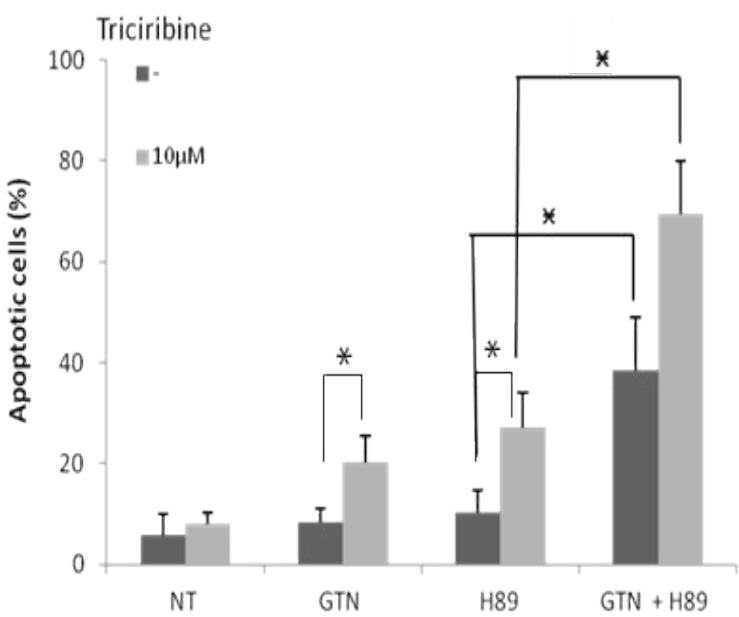

C

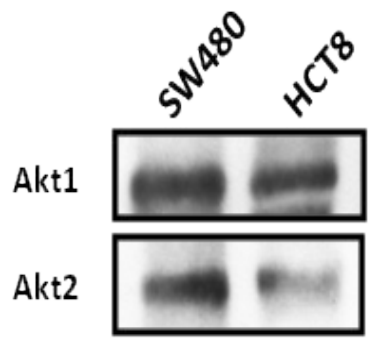

Figure 1: Sensitization of SW480 cells and HCT8 cells to GTN/triciribine combination by H89. Exponentially growing (A) SW480 cells ( $\left.3 \times 10^{5} / \mathrm{mL}\right)$ and (B) HCT8 cells $(3 \times 105 / \mathrm{mL})$ were pretreated for $1 \mathrm{~h} 30$ with an Akt specific inhibitor triciribine at indicated concentrations before exposure to GTN or/and H89 $(10 \mu \mathrm{M}$ each) for 24 hours or 48 hours. Apoptotic cells were counted after Hoechst 33342 staining. Results are the mean SD of 3 independent experiments. ${ }^{*} p<0.05$. (C) Western blot analysis of Akt1 and Akt2 isoforms in SW480 cells and HCT8 cells (1 representative of 3 independent experiments). 
Citation: Ali-Boina R, Cortier M, Decologne N, Racoeur-Godard C, Seignez C, et al. (2013) Activation of Akt by the Mammalian Target of Rapamycin Complex 2 Renders Colon Cancer Cells Sensitive to Apoptosis Induced by Nitric Oxide and Akt Inhibitor. J Carcinog Mutagen S8: 004. doi:10.4172/2157-2518.S8-004

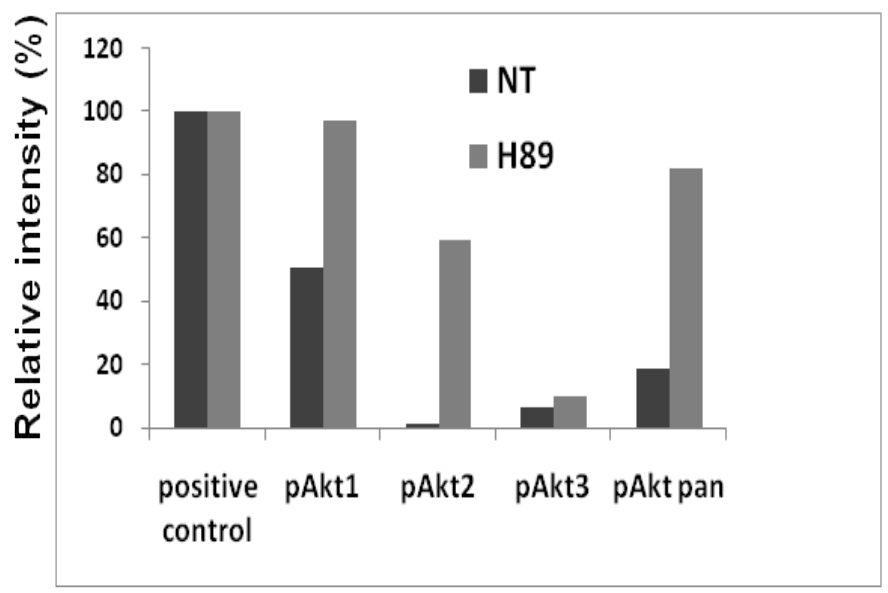

C

SW480

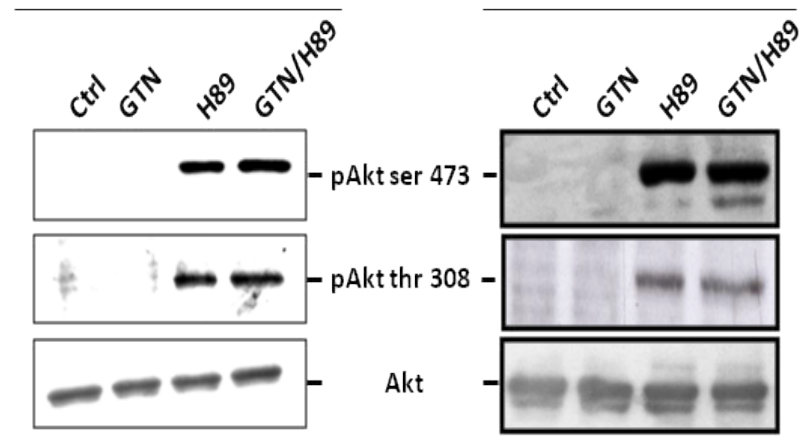

B

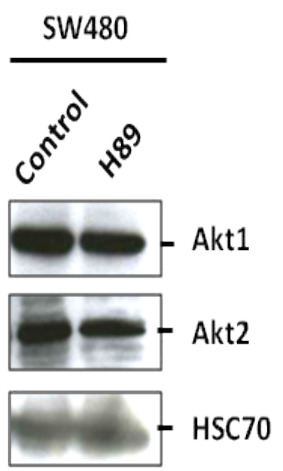

D

SW480

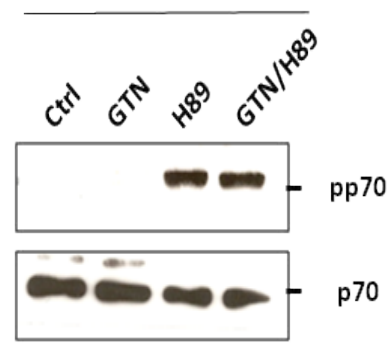

HCT8

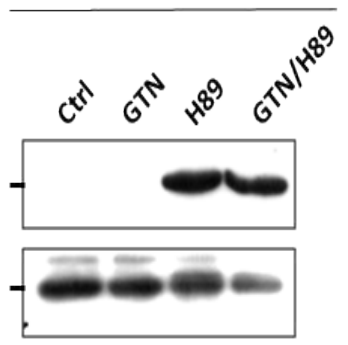

Figure 2: H89 induces phosphorylation of Akt on serine 473 and threonine 308 and the mTOR target kinase, p70S6K. (A) SW480 cells were treated for 48 hours with $\mathrm{H} 89(10 \mu \mathrm{M})$ or left untreated (NT). Cell lysates were analyzed with a phospho-MAPK Array kit to detect the phosphorylation status of Akt isoforms (Akt1, Akt2, Akt3). Each point was analyzed with image $\mathrm{J}$ software to express the results in guise of relative intensity. The positive control is an internal control supplied with the kit and represents $100 \%$ of the signal (pixel density). (B) Western blot analysis of Akt1 and Akt2 in SW480 cells after H89 treatment (10 $\mu$ M) for 48 hours. HSC70 was used as a control for equal protein loading expression (1 representative of 3 independent experiments). (C and D) SW480 cells $\left(3 \times 10^{5} / \mathrm{mL}\right)$ and HCT8 cells $\left(3 \times 10^{5} / \mathrm{mL}\right)$ were treated with GTN $(10 \mu \mathrm{M})$ or/and $\mathrm{H} 89(10 \mu \mathrm{M})$ or left untreated $(\mathrm{Ctrl})$ for 24 hours at $37^{\circ} \mathrm{C}$. Total proteins were obtained and subjected to western blot analysis for Akt, pAkt ser 473, pAkt thr 308 expression (C), p70 and pp70 expression (D) (1 representative of 3 independent experiments). Results have been obtained after a short exposure of the film (10 min). However, longer exposure of the film (30 min and more) permits the visualization of a slight expression of pAkt 1 in non treated cells (data not shown).

assessed by western blotting (Figure $2 \mathrm{~B}$ ). However, phosphorylation of Akt3 was difficult to detect in our experimental settings probably due to the low level of expression of this isoform in SW480 cells (data not shown). As Akt is phosphorylated and then activated on two key residues: Threonine $308\left(\mathrm{Thr}^{308}\right)$ and serine $473\left(\mathrm{Ser}^{473}\right)$, we examined the two cell lines for their expression of phosphorylated Akt (pAkt) at Thr308 (pAktThr ${ }^{308}$ ) or at $\operatorname{Ser}^{473}$ (pAktSer ${ }^{473}$ ) by western blot analysis. As shown in Figure 2C, H89 strongly increased the levels of both pAkt Thr ${ }^{308}$ and pAktSer ${ }^{473}$ in the two cell lines. It is noted that GTN did not induce the phosphorylation status of Akt, nor substantially enhanced the effect of H89 (Figure 2C). To demonstrate that phosphorylated Akt was active, we tested the effect of $\mathrm{H} 89$ on the phosphorylation status of Akt downstream effectors such as the kinase p70S6K1. Western blotting showed that phosphorylated p70S6K1 (pp70) was not detected in both SW480 and HCT-8 cells before and after treatment with GTN. In contrast, however, phosphorylated p70S6K1 was detected in both cell lines treated with $10 \mu \mathrm{M} \mathrm{H} 89$ for $24 \mathrm{~h}$ (Figure 2D). These results show for the first time that the protein kinase inhibitor H89 is a potent activator of the Akt/mTOR pathway in human colon cancer cells.

\section{Triciribine inhibits H89-mediated phosphorylation of Akt and mTOR signaling pathway}

We next asked whether H89-inducing activation of the Akt/ mTOR signaling pathway was affected by triciribine in colon cancer cells. To this end, we treated SW480 cells with $10 \mu \mathrm{M}$ H89 and/or $10 \mu \mathrm{M}$ GTN in the absence and presence of $10 \mu \mathrm{M}$ triciribine. After $24 \mathrm{~h}$ in culture, SW480 cells were lysed and examined by western blotting for the phosphorylation of Akt and the downstream kinase p70S6K1. Triciribine treatment completely abrogated H89-induced phosphorylation of Akt either on serine 473 or threonine 308 without affecting the whole protein expression (Figure $3 \mathrm{~A}$ ). Triciribine also inhibited H89-mediated phosphorylation of p70S6K1 (pp70) while the expression of the non phosphorylated protein ( $\mathrm{p} 70)$ remained 
Citation: Ali-Boina R, Cortier M, Decologne N, Racoeur-Godard C, Seignez C, et al. (2013) Activation of Akt by the Mammalian Target of Rapamycin Complex 2 Renders Colon Cancer Cells Sensitive to Apoptosis Induced by Nitric Oxide and Akt Inhibitor. J Carcinog Mutagen S8: 004. doi:10.4172/2157-2518.S8-004

Page 5 of 9

\begin{tabular}{|c|c|c|c|}
\hline & $\begin{array}{c}\text { Control } \\
\text { (\% relative to positive } \\
\text { control) }\end{array}$ & $\begin{array}{l}\mathrm{H} 89 \text { ( } \% \text { rela- } \\
\text { tive to positive } \\
\text { control) }\end{array}$ & $\begin{array}{c}\text { Ratio } \\
\text { H89/control }\end{array}$ \\
\hline ERk1 & 102 & 97 & 0,95 \\
\hline JNK1 & 9 & 2 & 0,24 \\
\hline JNK pan & 2 & 9 & 3,87 \\
\hline P38g & 12 & 3 & 0,25 \\
\hline P38d & 1 & 0 & 0,00 \\
\hline RSK1 & 29 & 6 & 0,23 \\
\hline GSK- 3a/b & 25 & 15 & 0,62 \\
\hline Akt-1 & 50 & 98 & 1,93 \\
\hline Akt- 2 & 1 & 60 & 43,00 \\
\hline ERK-1 & 100 & 92 & 0.92 \\
\hline JNK- 2 & 6 & 0 & 0,00 \\
\hline P38-2 & 51 & 37 & 0,72 \\
\hline P38b & 6 & 3 & 0,51 \\
\hline RSK2 & 0 & 0 & 0,00 \\
\hline GSK-3b & 0 & 0 & 1.08 \\
\hline Akt 3 & 6 & 10 & 1,57 \\
\hline Akt pan & 19 & 82 & 4,41 \\
\hline JNK 3 & 6 & 6 & 0,94 \\
\hline MSK 2 & 18 & 27 & 1,52 \\
\hline HSP 27 & 31 & 7 & 0,23 \\
\hline P 70 S6 kinase & 3 & 0 & 0,06 \\
\hline
\end{tabular}

Table 1: Phosphokinase profile of $\mathrm{H} 89$-stimulated SW480. Values represent the percentage of phosphorylated kinases relative to the positive control (\% relative to pos. Control), an internal control supplied with the kit and represents $100 \%$ of the signal, in untreated SW480 cells (control) or treated with $\mathrm{H} 89$ (H89). The ratio ( $\mathrm{H} 89 /$ control) represents the fold increase or decrease of phosphorylated kinases by $\mathrm{H} 89$.

unchanged (Figure 3B), confirming that triciribine was a potent inhibitor of Akt and mTOR pathway. It is noteworthy that the potential of $\mathrm{H} 89$ to phosphorylate Akt at serine 473 was higher as compared with the other members of $\mathrm{H}$ family (Figure $3 \mathrm{C}$ ). Phosphorylation of Akt at threonine 308 and p70S6K was faintly induced by the other family members of H89 (Figures 3C and 3D). Triciribine also abrogated the low level of Akt phosphorylated at serine 473 by $\mathrm{H} 7, \mathrm{H} 8$, and $\mathrm{H} 9$ (Figure 3C). These results indicate that triciribine is a potent inhibitor of H89-mediated Akt/mTOR activation in colon cancer cells.

\section{mTORC1 inhibition alone is not enough to enhance apoptosis induced by GTN/H89}

To examine how triciribine enhanced apoptosis triggered by GTN/ $\mathrm{H} 89$, the possible involvement of mTORC1 pathway was investigated. Similarly to triciribine effect, exposure of SW480 cells to $50 \mathrm{nM}$ rapamycin for $24 \mathrm{~h}$ completely abrogated phosphorylation of p70S6K1 induced by $\mathrm{H} 89$ or H89/GTN (Figure 4A). However, in these cells rapamycin did not affect GTN/H89-induced apoptosis (Figure 4B). Furthermore, when cells were transfected with specific siRNA, downregulating the expression of p70S6K1 (Figure 4C), exposure of these cells to H89/GTN did not create a synergistic effect as observed with triciribine in non transfected cells (Figure 4D). This suggests that mTORC1 inhibition is not essential in the signaling of triciribinemediated cell death enhancement.

\section{mTORC2 signaling inhibition could be involved in triciribine- mediated enhancement of apoptosis induced by GTN/H89}

As phosphorylation of Akt at serine 473, which is abrogated by

A

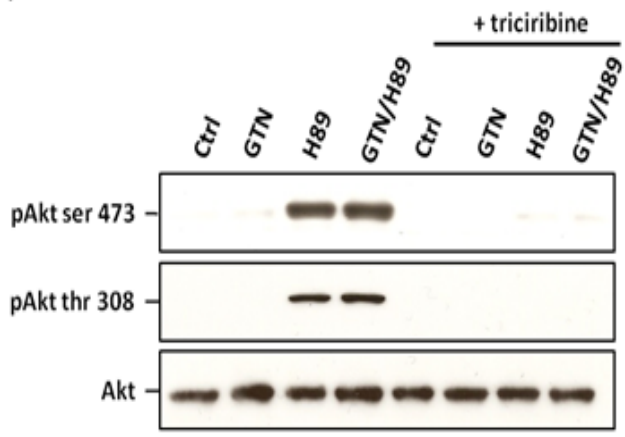

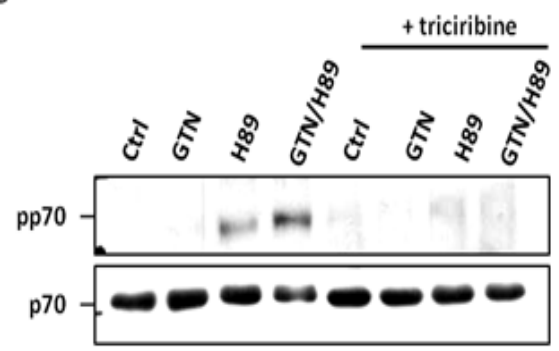

C

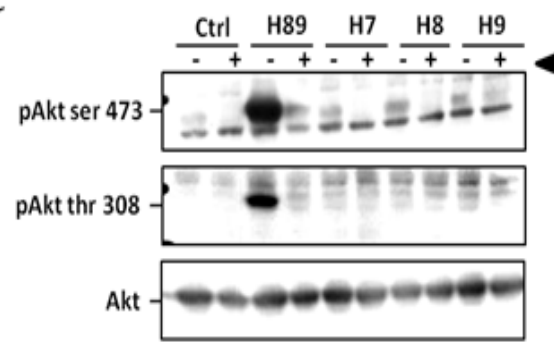

D

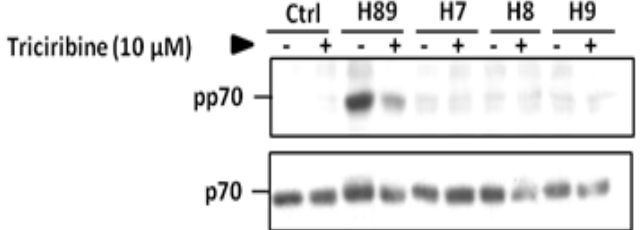

Figure 3: Triciribine abrogates the specific activation of Akt/mTOR signaling pathway by H89. SW480 cells $(3 \times 105 / \mathrm{mL})$ were pretreated for $1 \mathrm{~h} 30 \mathrm{with}$ triciribine $(10 \mu \mathrm{M})$ before exposure to GTN or/and H89 (10 $\mu \mathrm{M}$ each) for 24 hours. (A) Western blot analysis of Akt, pAkt ser 473 and pAkt thr 308 expression, (B) Western blot analysis of p70 and pp70. (1 representative of 3 independent experiments). (C and D) SW480 cells $\left(3 \times 10^{5} / \mathrm{mL}\right)$ were pretreated for $1 \mathrm{~h} 30$ with triciribine $(10 \mu \mathrm{M})$ before exposure to $\mathrm{H} 89, \mathrm{H} 7, \mathrm{H} 8$ and $\mathrm{H} 9$ (10 $\mu \mathrm{M}$ each) for 24 hours. Total protein was isolated and subjected to western blot analysis for (C) Akt, pAkt ser 473 , pAkt thr 308 expression (longer exposure of films has been required to detect slight expression of pAkt), (D) Western blot analysis of p70 and pp70 expression (1 representative of 3 independent experiments). 
Citation: Ali-Boina R, Cortier M, Decologne N, Racoeur-Godard C, Seignez C, et al. (2013) Activation of Akt by the Mammalian Target of Rapamycin Complex 2 Renders Colon Cancer Cells Sensitive to Apoptosis Induced by Nitric Oxide and Akt Inhibitor. J Carcinog Mutagen S8: 004. doi:10.4172/2157-2518.S8-004

A

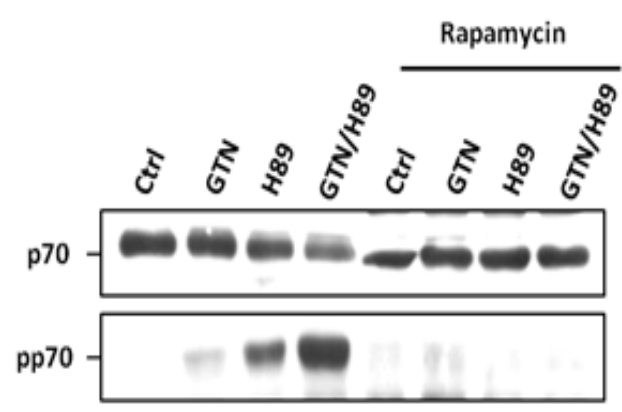

C

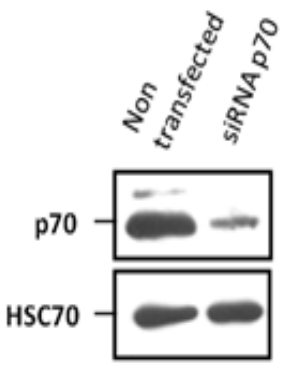

B

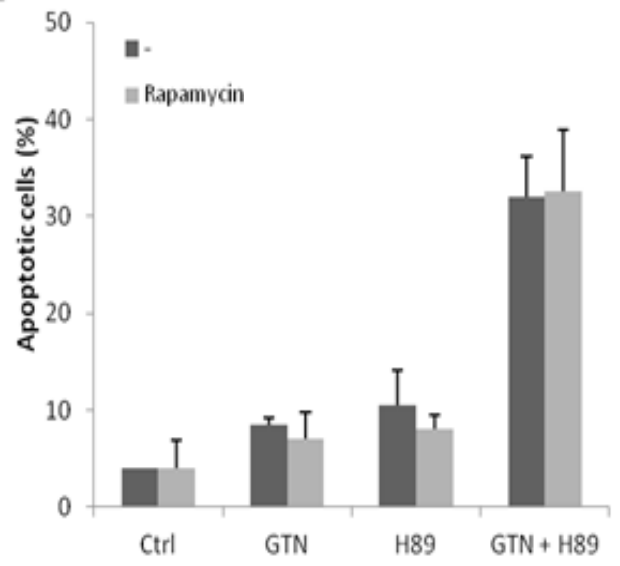

D

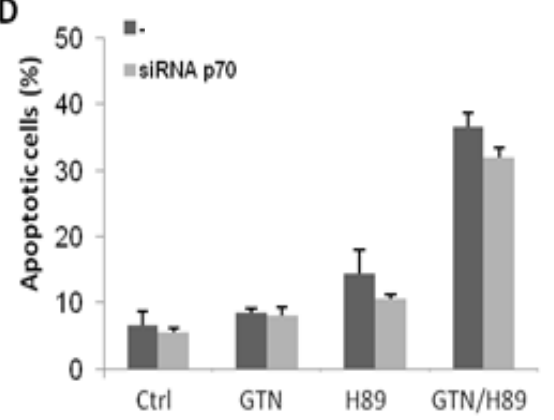

Figure 4: mTORC1 signaling inhibition is not sufficient to enhance apoptosis induced by GTN/H89. SW480 cells $\left(3 \times 10^{5} / \mathrm{mL}\right)$ were pretreated for $1 \mathrm{~h} 30$ with rapamycin $(50 \mathrm{nM})$ before exposure to GTN or/and H89 (10 $\mu \mathrm{M}$ each) (A) for 24 hours to analyze by western blot p70 and pp70 expression or (B) for $48 \mathrm{~h}$ to count apoptotic cells after Hoechst 33342 staining. (C) SW480 cells were transfected with a p70-specific siRNA. Total protein was isolated and subjected to western blot analysis for p70 expression. HSC70 was used as a control for equal protein loading (1 representative of 3 independent experiments). (D) p70-specific siRNA-transfected SW480 cells were treated with GTN or/and $\mathrm{H} 89\left(10 \mu \mathrm{M}\right.$ each) for $48 \mathrm{~h}$ at $37^{\circ} \mathrm{C}$. Then, apoptotic cells were counted after Hoechst 33342 staining (Results are the mean SD of 3 independent experiments).

triciribine, is mediated by mTORC2, the involvement of this complex was investigated. SW480 cells were transfected with specific siRNA, down-regulating the expression of rictor (Figure 5A). In these cells, phosphorylation of Akt at serine 473 by $\mathrm{H} 89$ was substantially diminished (Figure 5B). Further, cells transfected with rictor siRNA became more sensitive to apoptosis induced by GTN/H89 (Figure 5C). These results provide evidence that triciribine enhances GTN/H89induced apoptosis of human colon cancer cells by affecting mTORC2 but not mTORC1 signaling pathway.

\section{pAkt $^{473}$ expression in colon cancer tumor cells}

We also attempted to determine whether phosphorylated Akt at serine 473 was expressed in colon cancer cells from patients. By immunohistochemistry, we observed that the tumour cells of three patients tested exhibited a clear staining with an anti- pAkt $^{\text {Ser473 }}$ (Figure 6, right panel) as compared to the healthy tissue (Figure 6, left panel). Although the few numbers of patients tested our results indicated that as opposed to the cell lines tumor cells might express pAkt ${ }^{\mathrm{Ser} 473}$.

\section{Discussion}

Colorectal cancer is one of the most common human malignancies. Despite recent advances in EGFR and Pi3K/Akt/mTOR-targeted therapies, it remains a leading cause of cancer-related death and urgently need new therapies to overcome the resistance to these latter treatments. We have previously shown that nitric oxide triggered and sensitized colon cancer cells to cytotoxic agents [22,24]. Because these studies suggested that $\mathrm{NO}$ is a promising agent for new adjuvant therapies, the search of combination of NO and some protein kinase inhibitors, including those targeting the oncogenic kinases of Pi3K/ Akt/mTOR pathway was conducted. In this study, we show for the first time that the combination of the NO donor GTN and two protein kinase inhibitors: the non specific PKA inhibitor H89 and the specific Akt inhibitor triciribine, results in the induction of apoptosis of human colon cancer cells. The results are consistent with data which showed that combination of drugs that blocks multiple kinase cell growth pathways leads to the inhibition of cell cycle progression and growth of colorectal carcinoma cells $[25,26]$. As several reports have suggested that tumors with elevated level of phospho-Akt are most likely to respond to Akt inhibitors $[27,28]$ the activation status of Akt has been evaluated. Our results showed that $\mathrm{H} 89$ induced Akt activation as attested by its phosphorylation at serine 473 and threonine 308. Such effect seems to restrain apoptosis induced by GTN/H89, since inhibition of Akt activation by triciribine strongly exacerbated cell death. Although the molecular mechanism by which GTN unlocks colorectal cancer cell resistance is not deciphered, NO may exert its pro-apoptotic effect by altering the Akt inhibitors-mediated activation of RTKs as described by 
Citation: Ali-Boina R, Cortier M, Decologne N, Racoeur-Godard C, Seignez C, et al. (2013) Activation of Akt by the Mammalian Target of Rapamycin Complex 2 Renders Colon Cancer Cells Sensitive to Apoptosis Induced by Nitric Oxide and Akt Inhibitor. J Carcinog Mutagen S8: 004. doi:10.4172/2157-2518.S8-004

A

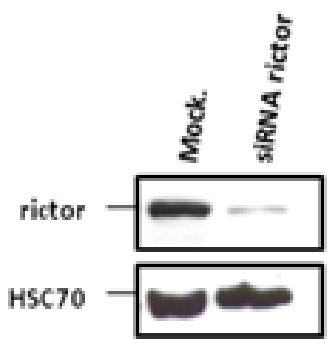

C

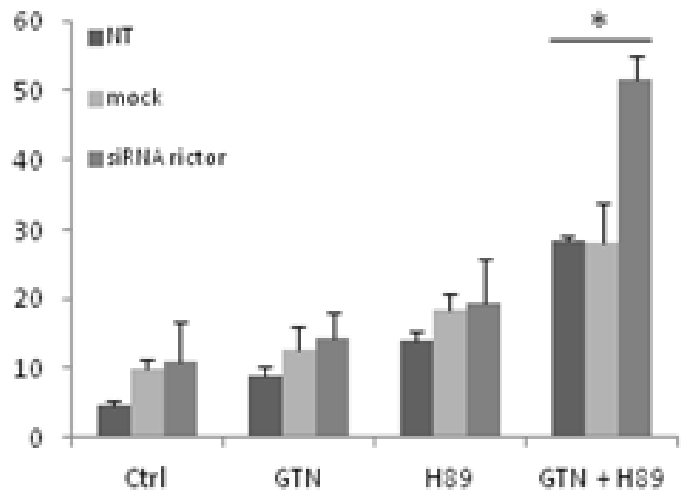

B

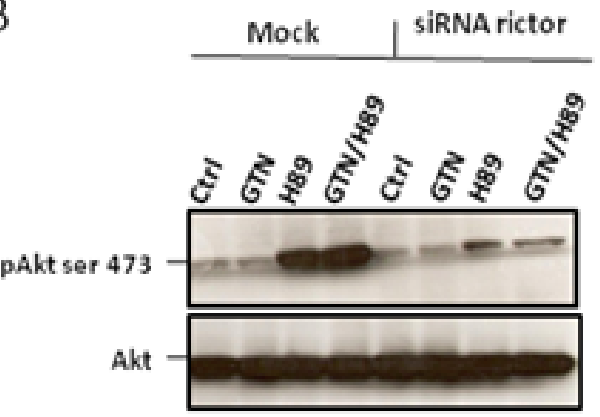
control siRNA (mock) $(20 \mathrm{nM}$ each) for 48 hours. Total protein was isolated and subjected to western blot analysis for rictor expression. HSC70 was used as a control for equal protein loading (1 representative of 2 independent experiments). (B) Transfected cells were treated with GTN or/and H89 (10 $\mu \mathrm{M}$ each) for 24 hours to analyze by western blot Akt and pAkt ser 473 expression (1 representative of 2 independent experiments). (C) Transfected cells were treated with GTN or/and H89 (10 $\mu \mathrm{M}$ each) for 48 hours and apoptotic cells were counted after Hoechst 33342 staining (Results are the mean SD of 2 independent experiments).
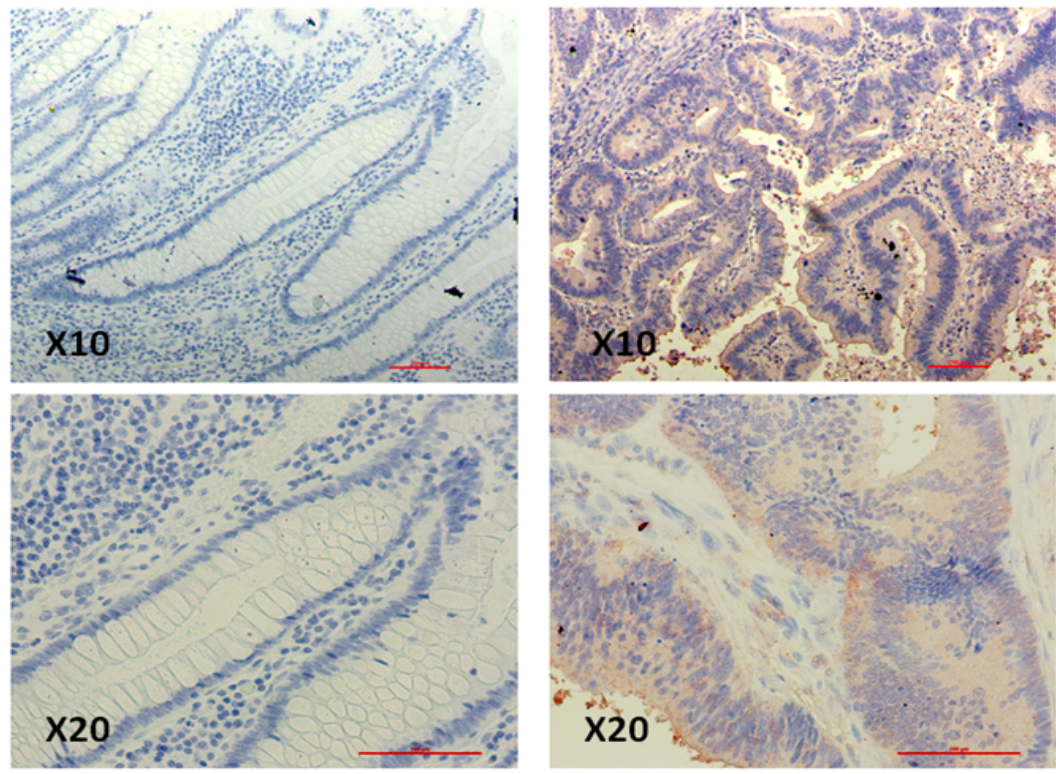

Figure 6: $\mathrm{pAkt}^{473}$ was expressed in colon cancer tumor cells. Immunohistochemical staining of phosphorylated Akt in paraffin-embedded human colon tumours using phospho-Akt (Ser473) antibody (IHC specific). Representative immunohistochemical staining of phospho-Akt paraffin fixed specimens. Expression of phosphorylated Akt was visualised in colon cancer tissue (right panels, brown) compared to normal colon tissue (left panels). 
Citation: Ali-Boina R, Cortier M, Decologne N, Racoeur-Godard C, Seignez C, et al. (2013) Activation of Akt by the Mammalian Target of Rapamycin Complex 2 Renders Colon Cancer Cells Sensitive to Apoptosis Induced by Nitric Oxide and Akt Inhibitor. J Carcinog Mutagen S8: 004. doi:10.4172/2157-2518.S8-004

Page 8 of 9

Chandarlapaty et al. [29]. It is noteworthy that three RTKs, epidermal growth factor 3 (EGFR-3) or HER3, insulin growth receptor 1 (IGF-1R) and macrophage-stimulating protein receptor (MSPR) are activated in colon cancer cells including SW480 [30,31]. As NO is able to inhibit the function of IGF-1R [32], GTN could render cancer cells sensitive to apoptosis induced by $\mathrm{H} 89$ and triciribine. $\mathrm{NO}$ is also able to reversibly inhibits the EGFR tyrosine kinase [33] which is highly expressed and activated in colorectal carcinomas and cell lines including SW480 [34]. In this study, we also show that $\mathrm{H} 89$ activated mTORC1, a downstream pathway activated by Akt. Although this complex is activated it seems not involved in cell resistance since its inhibition by rapamycin does not sensitize cells to apoptosis-induced by GTN/H89. This is consistent with results showing that SW480 and HCT8 cells are resistant to rapamycininduced tumor growth inhibition and cell death $[35,36]$. In contrast, inhibition of mTORC2 and then phosphorylation of Akt at serine 473 enhanced GTN/H89 triggered apoptosis as triciribine does, suggesting that in our model of rapamycin-resistant colon cancer cells, mTORC2 plays a role in the resistance of cells to GTN/H89-induced apoptosis. These results are consistent with reports showing that inhibition of mTORC2 reduces colon cancer cell proliferation in vitro and tumor xenograft formation in vivo [37]. Collectively, our current study describes for the first time the induction of cancer cell apoptosis by NO and the inhibition of oncogenic protein kinase. Actually, human colon cancer cell died by apoptosis when the NO donor GTN was associated with a protein kinase inhibitor $\mathrm{H} 89$, that functions as a potent activator of the Akt/mTOR signaling pathway, and triciribine a specific inhibitor of Akt.

These findings indicate a great value for future preclinical investigations, and provide a piece of proof-of-concept evidence for potential combination with GTN/H89/triciribine for enhanced colon cancer cell killing in a phase I clinical trial. Indeed, several published studies have reported the effective and safe use of GTN alone or associated with chemotherapy in patients with lung or prostate cancer [20,21]. In recent phase I/II clinical trials in patients with advanced solid tumors [38] or with advanced hematological malignancies [39] administration of triciribine resulted in inhibition of Akt in tumor cells. More importantly, triciribine was safe and well tolerated. Recently, it has been shown that H89 augmented the apoptosis of glioma cells induced by the EGFR tyrosine kinase inhibitor gefitinib through Bad dephosphorylation, Bax mitochondrial translocation, and caspase-9/ caspase-3 activation [40].

\section{Acknowledgments}

The authors thank Pr François Ghiringhelli and Dr Laurent Arnoud (AntiCancer Georges François Leclerc Centre, Dijon, France) for their support for our translational research by providing human biopsy samples. This work was supported by grants from Ligue Nationale Contre le Cancer (comité inter-régional du Grand-Est) and from FEDER 2009-0431SG0003S01173 from European Union and no. 32403 from Regional Council of Burgundy. RBA is supported by a doctoral fellowship from Regional Council of Burgundy and EPHE.

The authors do not have any competing financial interests in relation of the work described.

\section{References}

1. Jemal A, Siegel R, Xu J, Ward E (2010) Cancer statistics, 2010. CA Cancer J Clin 60: 277-300.

2. Wolpin BM, Mayer RJ (2008) Systemic treatment of colorectal cancer. Gastroenterology 134: 1296-1310.

3. Hollande F, Pannequin J, Joubert D (2010) The long road to colorectal cancer therapy: searching for the right signals. Drug Resist Updat 13: 44-56.
4. Liang J, Slingerland JM (2003) Multiple roles of the PI3K/PKB (Akt) pathway in cell cycle progression. Cell Cycle 2: 339-345.

5. Zhou BP, Liao Y, Xia W, Spohn B, Lee MH, et al. (2001) Cytoplasmic localization of p21Cip1/WAF1 by Akt-induced phosphorylation in HER-2/neuoverexpressing cells. Nat Cell Biol 3: 245-252.

6. Cardone MH, Roy N, Stennicke HR, Salvesen GS, Franke TF, et al. (1998) Regulation of cell death protease caspase- 9 by phosphorylation. Science 282 1318-1321.

7. Datta SR, Dudek H, Tao X, Masters S, Fu H, et al. (1997) Akt phosphorylation of BAD couples survival signals to the cell-intrinsic death machinery. Cell 91 : 231-241.

8. Sarbassov DD, Guertin DA, Ali SM, Sabatini DM (2005) Phosphorylation and regulation of Akt/PKB by the rictor-mTOR complex. Science 307: 1098-1101.

9. Guertin DA, Sabatini DM (2007) Defining the role of mTOR in cancer. Cancer Cell 12: 9-22.

10. Vivanco I, Sawyers CL (2002) The phosphatidylinositol 3-Kinase AKT pathway in human cancer. Nat Rev Cancer 2: 489-501.

11. Rychahou PG, Kang J, Gulhati P, Doan HQ, Chen LA, et al. (2008) Akt2 overexpression plays a critical role in the establishment of colorectal cancer metastasis. Proc Natl Acad Sci U S A 105: 20315-20320.

12. Jiang BH, Liu LZ (2008) Role of mTOR in anticancer drug resistance: perspectives for improved drug treatment. Drug Resist Updat 11: 63-76.

13. Brognard J, Clark AS, Ni Y, Dennis PA (2001) Akt/protein kinase B is constitutively active in non-small cell lung cancer cells and promotes cellular survival and resistance to chemotherapy and radiation. Cancer Res 61: 3986-3997.

14. Nakashio A, Fujita N, Rokudai S, Sato S, Tsuruo T (2000) Prevention of phosphatidylinositol 3'-kinase-Akt survival signaling pathway during topotecaninduced apoptosis. Cancer Res 60: 5303-5309.

15. MacKeigan JP, Taxman DJ, Hunter D, Earp HS 3rd, Graves LM, et al. (2002) Inactivation of the antiapoptotic phosphatidylinositol 3-kinase-Akt pathway by the combined treatment of taxol and mitogen-activated protein kinase kinase inhibition. Clin Cancer Res 8: 2091-2099.

16. Pervin S, Singh R, Chaudhuri G (2003) Nitric-oxide-induced Bax integration into the mitochondrial membrane commits MDA-MB-468 cells to apoptosis: essential role of Akt. Cancer Res 63: 5470-5479.

17. Yang SX, Costantino JP, Kim C, Mamounas EP, Nguyen D, et al. (2010) Akt phosphorylation at Ser473 predicts benefit of paclitaxel chemotherapy in nodepositive breast cancer. J Clin Oncol 28: 2974-2981.

18. Abrams J (1987) Glyceryl trinitrate (nitroglycerin) and the organic nitrates Choosing the method of administration. Drugs 34: 391-403.

19. Hashimoto S, Kobayashi A (2003) Clinical pharmacokinetics and pharmacodynamics of glyceryl trinitrate and its metabolites. Clin Pharmacokinet 42: 205-221.

20. Yasuda H, Yamaya M, Nakayama K, Sasaki T, Ebihara S, et al. (2006) Randomized phase II trial comparing nitroglycerin plus vinorelbine and cisplatin with vinorelbine and cisplatin alone in previously untreated stage IIIB/IV nonsmall-cell lung cancer. J Clin Oncol 24: 688-694

21. Siemens DR, Heaton JP, Adams MA, Kawakami J, Graham CH (2009) Phase II study of nitric oxide donor for men with increasing prostate-specific antigen level after surgery or radiotherapy for prostate cancer. Urology 74: 878-883.

22. Millet A, Bettaieb A, Renaud F, Prevotat L, Hammann A, et al. (2002) Influence of the nitric oxide donor glyceryl trinitrate on apoptotic pathways in human colon cancer cells. Gastroenterology 123: 235-246.

23. Huerta S, Chilka S, Bonavida B (2008) Nitric oxide donors: novel cance therapeutics (review). Int J Oncol 33: 909-927.

24. Leon-Bollotte L, Subramaniam S, Cauvard O, Plenchette-Colas S, Paul C, et al (2011) S-nitrosylation of the death receptor fas promotes fas ligand-mediated apoptosis in cancer cells. Gastroenterology 140: 2009-2018.

25. Hezel AF, Ryan DP (2007) Emerging therapies for colorectal cancer. Expert Opin Investig Drugs 16: 867-876.

26. Zhang YJ, Tian XQ, Sun DF, Zhao SL, Xiong H, et al. (2009) Combined inhibition of MEK and mTOR signaling inhibits initiation and progression of colorectal cancer. Cancer Invest 27: 273-285. 
Citation: Ali-Boina R, Cortier M, Decologne N, Racoeur-Godard C, Seignez C, et al. (2013) Activation of Akt by the Mammalian Target of Rapamycin Complex 2 Renders Colon Cancer Cells Sensitive to Apoptosis Induced by Nitric Oxide and Akt Inhibitor. J Carcinog Mutagen S8: 004. doi:10.4172/2157-2518.S8-004

Page 9 of 9

27. Davies SP, Reddy H, Caivano M, Cohen P (2000) Specificity and mechanism of action of some commonly used protein kinase inhibitors. Biochem $\mathrm{J} 351$ : 95-105.

28. Vasudevan KM, Barbie DA, Davies MA, Rabinovsky R, McNear CJ, et al. (2009) AKT-independent signaling downstream of oncogenic PIK3CA mutations in human cancer. Cancer Cell 16: 21-32.

29. Chandarlapaty S, Sawai A, Scaltriti M, Rodrik-Outmezguine V, Grbovic-Huezo O, et al. (2011) AKT inhibition relieves feedback suppression of receptor tyrosine kinase expression and activity. Cancer Cell 19: 58-71.

30. Kelly RG, Nally K, Shanahan F, O'Connell J (2002) Type I insulin-like growth factor receptor expression on colorectal adenocarcinoma cell lines is decreased in response to the chemopreventive agent $\mathrm{N}$-acetyl-I-cysteine. Ann $\mathrm{N}$ Y Acad Sci 973: 555-558.

31. Morishita A, Gong J, Nomura T, Yoshida H, Izuishi K, et al. (2010) The use of protein array to identify targetable receptor tyrosine kinases for treatment of human colon cancer. Int J Oncol 37: 829-835.

32. Studer RK (2004) Nitric oxide decreases IGF-1 receptor function in vitro; glutathione depletion enhances this effect in vivo. Osteoarthritis Cartilage 12 863-869.

33. Estrada C, Gómez C, Martín-Nieto J, De Frutos T, Jiménez A, et al. (1997) Nitric oxide reversibly inhibits the epidermal growth factor receptor tyrosine kinase. Biochem J 326: 369-376.

34. Ciardiello F, Caputo R, Bianco R, Damiano V, Fontanini G, et al. (2001) Inhibition of growth factor production and angiogenesis in human cancer cells by ZD1839 (Iressa), a selective epidermal growth factor receptor tyrosine kinase inhibitor Clin Cancer Res 7: 1459-1465.

35. Gulhati P Cai Q, Li J, Liu J, Rychahou PG, et al. (2009) Targeted inhibition of mammalian target of rapamycin signaling inhibits tumorigenesis of colorectal cancer. Clin Cancer Res 15: 7207-7216.

36. Dilling MB, Germain GS, Dudkin L, Jayaraman AL, Zhang X, et al. (2002) $4 \mathrm{E}$-binding proteins, the suppressors of eukaryotic initiation factor $4 \mathrm{E}$, are down-regulated in cells with acquired or intrinsic resistance to rapamycin. J Biol Chem 277: 13907-13917.

37. Roulin D, Cerantola Y, Dormond-Meuwly A, Demartines N, Dormond O (2010) Targeting mTORC2 inhibits colon cancer cell proliferation in vitro and tumor formation in vivo. Mol Cancer 9: 57

38. Garrett CR, Coppola D, Wenham RM, Cubitt CL, Neuger AM, et al. (2011) Phase pharmacokinetic and pharmacodynamic study of triciribine phosphate monohydrate, a small-molecule inhibitor of AKT phosphorylation, in adult subjects with solid tumors containing activated AKT. Invest New Drugs 29: 1381-1389.

39. Sampath D, Malik A, Plunkett W, Nowak B, Williams B, et al. (2013) Phase I clinical, pharmacokinetic, and pharmacodynamic study of the Akt-inhibitor triciribine phosphate monohydrate in patients with advanced hematologic malignancies. Leuk Res 37: 1461-1467.

40. Chang CY, Shen CC, Su HL, Chen CJ (2011) Gefitinib induces apoptosis in human glioma cells by targeting Bad phosphorylation. J Neurooncol 105: 507-522.
This article was originally published in a special issue, Anticancer Drugs handled by Editor(s). Dr. Philippe Becuwe, Henri Poincaré's University of Nancy, France 